\title{
Modic changes of the lumbar spine-their association with the lumbar sagittal parameters: A retrospective imaging study
}

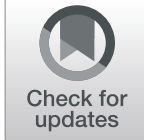

\author{
Xiaoping $\mathrm{Mu}^{1}$, Wei Peng ${ }^{2}$, Chengqiang Yu ${ }^{1}$, Jian Xiong ${ }^{3}$, Jianxun $\mathrm{Wei}^{1}$, Yufu $\mathrm{Ou}^{1^{*}}$ and Chenglong Wang ${ }^{{ }^{*}}$
}

\begin{abstract}
Background: The Lumbar sagittal parameters might be related to modic changes (MCs). However, studies on this topic have rarely been reported. The aim of this study was to identify the relationships between the lumbar sagittal parameters and the development of MCs.

Methods: The lumbar sagittal parameters of 321 patients with chronic low back pain from May 2016 to August 2018 were measured on X-ray by using Surgimap surgical planning software. Univariable analyses were used to test the potential variables of interest. Logistic regression models were then performed for the significant parameters to identify the independent factors associated with the development of MCs.

Results: More patients in the MCs group were older with more number of female than in the disc degeneration group $(p<0.05)$. In the univariate analysis, significant differences were detected for the parameters of lumbar lordosis, sacral slope, intervertebral height index, endplate concave angle, and intervertebral angle only at the L5/S1 level between the two groups. The results of logistic regression analysis showed that a smaller intervertebral height index was positively associated with the development of MCs at the level of L3/4 $(p<0.05)$. However, the positive role of gender was only for MCs at the L5/S1 level $(p<0.05)$.

Conclusions: The results of this study revealed that there were negative relationships between the lumbar sagittal parameters and MCs. Furthermore, being female and having a narrow intervertebral space were the independent risk factors for the development of MCs at the corresponding lumbar levels. Interestingly, body mass index might be not associated with MCs for the Chinese population.
\end{abstract}

Keywords: Lumbar spine, Vertebral endplate signal changes, Modic changes, Lumbar sagittal parameters, Correlative factors, Imaging study

\section{Background}

Vertebral endplate subchondral bone signal changes, also known as modic changes (MCs), are detected clearly on magnetic resonance imaging (MRI). de Roos et al. [1] initially reported on the abnormal signal changes in the vertebral body marrow adjacent to the endplates in the

\footnotetext{
* Correspondence: Ou.YF1972@gmail.com; wang11doctor@foxmail.com 'Department of Orthopedics, People's Hospital of Guangxi Zhuang Autonomous Region, Nanning 530021, China

Full list of author information is available at the end of the article
}

patients with lumbar disc degeneration. Subsequently, Modic et al. [2, 3] described in detail their histological features and the three types of MCs based on their appearance on T1-weighted and T2-weighted images in 1988.

In recent years, more attention has been paid to MCs, which are positively associated with chronic low back pain (CLBP) [4, 5]. Although MCs have been studied for several decades, the potential pain mechanisms are still unclear or controversial. Endplate inflammation or lowtoxicity infection may be the cause of pain for patients 
with MCs [6-8]. However, several studies have shown that spinal instability also plays an important role in the occurrence of pain $[9,10]$.

Spine stability is determined by the shape of the spine, composed of several normal spinal motor units. Moreover, the shape of the spine can be reflected by sagittal balance, which allows humans to maintain the standing position with little muscle effort [11]. Previous studies have suggested that sagittal balance status, as an independent predictor, not only affects the clinical symptoms of many spinal diseases, but also plays a positive role in the prognosis of patients who underwent appropriate treatment $[12,13]$. In addition, studies of sagittal parameters in MCs of the cervical spine showed that the $\mathrm{T} 1$ slope [14] and the C2-C7 Cobb angle [15] are potential risk factors for the development of MCs.

Lumbar sagittal parameters may also be related to the development of MCs, but which ones have strongly associations with MCs remain unpredictable. To the best of our knowledge, data on the correlation between MCs and sagittal parameters in the lumbar spine are limited in the literature. Therefore, the main purpose of this study was to identify the relationships between lumbar sagittal parameters and development of MCs.

\section{Materials and methods}

\section{Patients population}

In this retrospective study, the sample cohort was derived from 1019 consecutive patients with lumbar disc degenerative diseases referred for a standard lumbar Xray (standing position) and MRI (supine position) from May 2016 to August 2018 in our clinic. Most patients had a history of low back pain and their symptoms met the diagnostic criteria for non-specific CLBP $[16,17]$. The duration of symptoms ranged from 3.8 to 8.7 months. In order to avoid the impact of previous treatments, only those patients who initially sought medical help for CLBP and did not receive any prior treatment were included. In addition, only adult patients whose disc degeneration (DD) grade was rated as grade 3 or greater in the Pfirrmann classification were included. The exclusion criteria included a history of lumbar surgery, spinal deformities, spinal infection, tumor, rheumatoid arthritis, and abnormal gait and posture caused by disability of the lower extremity or other diseases.

Finally, we identified 321 patients. Of which, 138 patients ( 81 females and 57 males) had MCs, with a mean age of 52.64 years, were included in the MCs group. Considering that DD has been shown to be closely associated with MCs $[4,5]$ and that lumbar segmental stability has been determined for both the lumbar disc and the endplate [9], the remaining 183 patients without MCs (73 females and 110 males; mean age, 48.99 years), with grade 3 or greater of DD, were allocated to the DD group. The study population selection process is shown in Fig. 1.

All patients allowed us to review their medical records and signed the relevant informed consent. The study protocol was approved by the Institutional Review Board of the People's Hospital of Guangxi Zhuang Autonomous Region (no. 2016-12). This clinical investigation was conducted in strict accordance with the principles of the Declaration of Helsinki.

\section{Imaging evaluation and measurement}

The lumbar X-ray (standing position) and MRI (supine position) examination were performed in accordance with the standard scanning procedure. Two experienced observers (M.X.P and W.C.L) evaluated and measured all patients images blinded to the patients demographics and clinical profiles by using the Surgimap surgical planning software (version 2.2.15, Globus Medical, Inc., Audubon, PA, USA).

Based on the classification system proposed by Modic et al. [2, 3], all MCs were divided into three categories from T1- and T2-weighted images: type I, hypointense on T1-weighted and hyperintense on T2-weighted images; type II, hyperintense both on T1- and T2-weighted images; and type III, hypointense on both T1- and T2weighted images. Based on the grading method proposed by Pfirrmann [18], DD was classified into five grades from T2-weighted imaging (Table 1).

Lumbar lordosis (LL) was defined as an angle formed by two oblique lines through and parallel to the L1 and S1 cranial endplates, respectively. Sacral slope (SS) was defined as an angle between a horizontal line and the cranial endplate of $\mathrm{S} 1$. The endplate concave angle (ECA) was measured as an angle formed by the lines drawn from the bottom or summit of the arc along to their endpoints. The intervertebral height index (IHI) = (anterior disc height + posterior disc height)/(superior disc diameter + inferior disc diameter $) \times 100 \%$. The intervertebral angle (IVA) was measured as the angle of two lines through and parallel to the cranial and caudal endplates (Fig. 2).

\section{Statistical analysis}

IBM SPSS Statistic software (Version 21.0; IBM Corp., Armonk, NY, USA) was used for the statistical analyses. The main manifestations of the data results are presented as the mean \pm standard deviation (SD). Appropriate statistical methods (Mann-Whitney $U$ test or $t$ test for measurement data, and the $\chi^{2}$ test for count data) were performed to detect the difference between the MCs and DD groups. The potential variables of interest were tested first. Subsequently, logistic regression models were performed for the significant parameters to identify the independent factors associated with the 


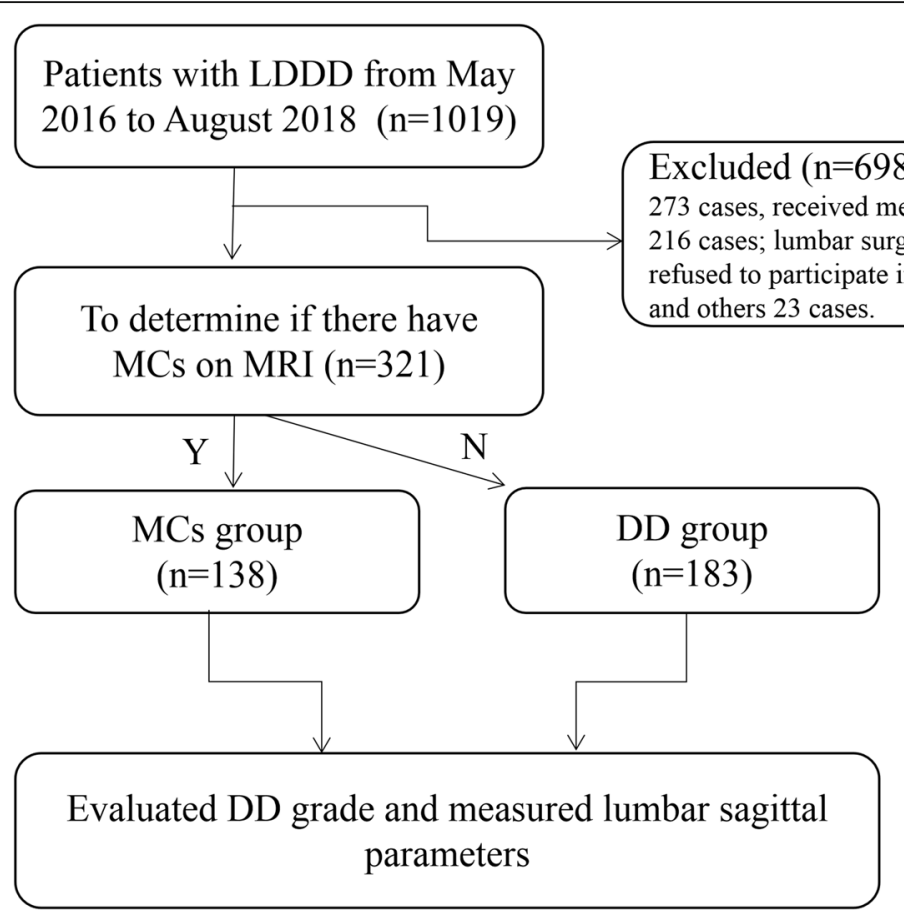

Fig. 1 The selection process of study population. LDDD: lumbar degenerative disc disease; MRI: magnetic resonance imaging; MCs: Modic changes; DD: disc degeneration

development of MCs. The intraclass correlation coefficient (ICC) was used to evaluated the inter-observer and intra-observer variability bias. Statistically significant differences were defined as those having a two-tailed $p$ value $<0.05$.

\section{Results}

All of the X-ray and MRI images were reviewed in accordance with the study protocol. Finally, 536 lumbar segments with grade 3 or greater of DD (MCs group: 158 lumbar segments from 138 patients; DD group: 378 lumbar segments from 183 patients) were measured for the sagittal parameters on lumbar X-ray images. Due to a lack of sufficient samples (MCs group at L1/2: 1 cases;
MCs group at L2/3: 3 cases), the parameters of L1/2 and L2/3 could not be analyzed in this study.

\section{Prevalence of MCs and patient demographics}

Overall, 138 patients had MCs (42.99\%). The most common distribution of MCs was at the L5/S1 (53.80\%) and L4/L5 (32.91\%) level, with type II (69.57\%) being the most common. The incidence of MCs in females (58.70\%) was higher than in males (41.30\%). The characteristics of patients in these two groups are shown in Table 2. No significant differences were found in the body mass index (BMI), white blood cell count (WBC), and the C-reactive protein (CRP) level between the two groups ( $p>$ 0.05). However, older age and female sex were the

Table 1 Pfirrmann grading system of lumbar disc degeneration

\begin{tabular}{|c|c|c|c|c|}
\hline Grade & Structure & $\begin{array}{l}\text { Distinction of nucleus and } \\
\text { annulus }\end{array}$ & Signal intensity & Disc height \\
\hline I & Homogeneous, bright white & Clear & Hyperintense, isointense to CSF & Normal \\
\hline$\|$ & $\begin{array}{l}\text { Inhomogeneous with or without horizontal } \\
\text { bands }\end{array}$ & Clear & Hyperintense, isointense to CSF & Normal \\
\hline III & Inhomogeneous, gray & Unclear & Intermediate to CSF & Normal to slightly decreased \\
\hline IV & Inhomogeneous, gray to black & Lost & $\begin{array}{l}\text { Intermediate to hypointense to } \\
\text { CSF }\end{array}$ & $\begin{array}{l}\text { Normal to moderately } \\
\text { decreased }\end{array}$ \\
\hline V & Inhomogeneous black & Lost & Hypointense to CSF & Collapsed \\
\hline
\end{tabular}




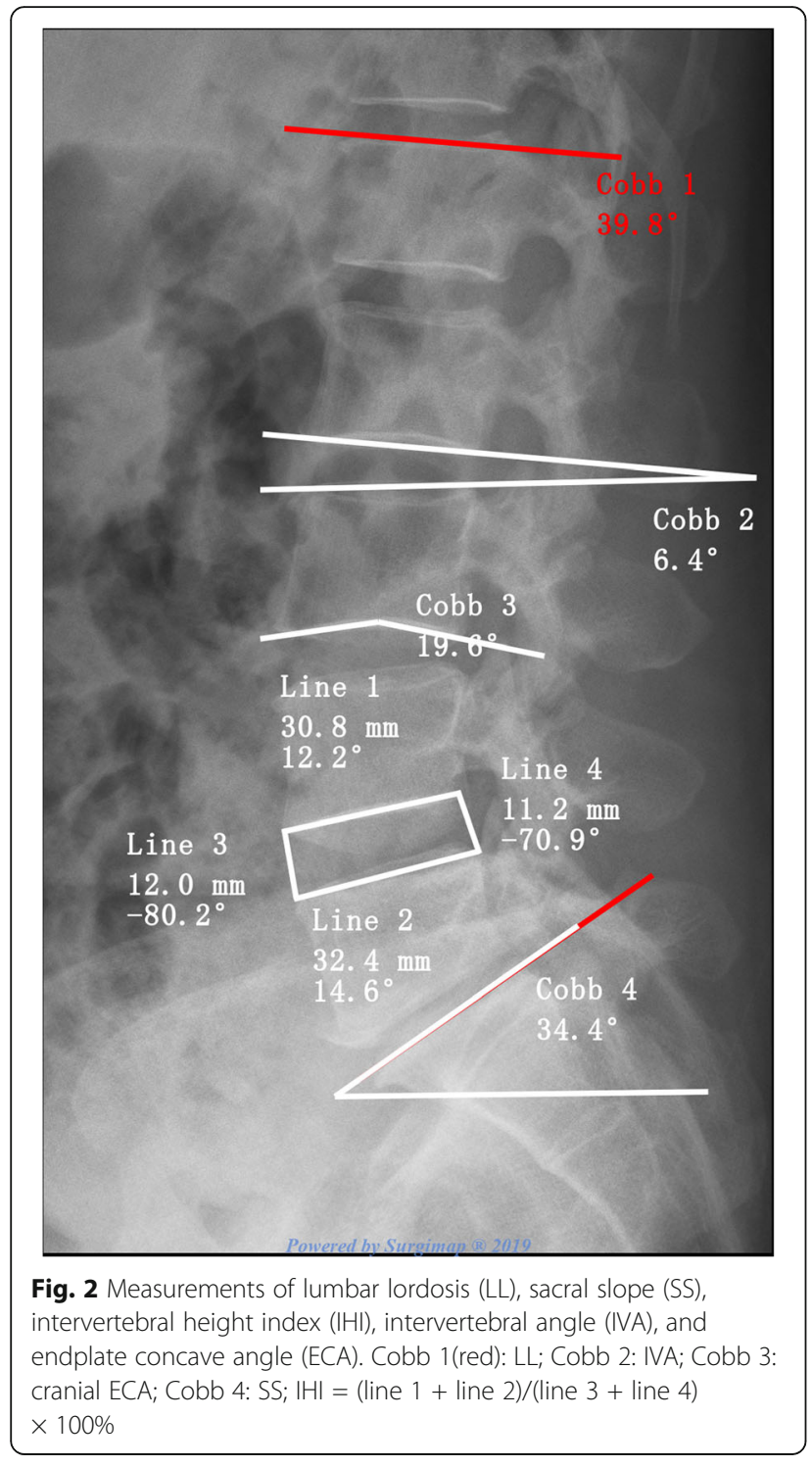

most common characteristics in patients with MCs compared with patients in the DD group $(p<0.05)$.

\section{Inter-observer and intra-observer reliability}

Excellent agreement was observed between the reviewers for the classification of MCs (ICC value 0.94), their types

Table 2 The patients' demographics

\begin{tabular}{lllll}
\hline Items & $\begin{array}{l}\text { MCs group } \\
(n=138)\end{array}$ & $\begin{array}{l}\text { DD group } \\
(n=183)\end{array}$ & $z / x^{2}$ & $p$ \\
\hline Age (years) & $52.64 \pm 11.69$ & $48.99 \pm 13.66$ & 2.579 & 0.010 \\
Gender (m/f) & $57 / 81$ & $110 / 73$ & 11.147 & 0.001 \\
BMI & $22.80 \pm 2.85$ & $22.70 \pm 2.50$ & 0.348 & 0.728 \\
WBC (+) & $8.11 \pm 2.79$ & $7.74 \pm 2.54$ & -1.051 & 0.293 \\
CRP $(+)$ & $8.65 \pm 17.18$ & $7.01 \pm 9.07$ & -0.483 & 0.629 \\
\hline
\end{tabular}

(ICC value 0.87), and grade of DD (ICC value 0.86 ). There was the substantial agreement between the two reviewers on the assessment of LL (ICC value 0.79), SS (ICC value 0.71 ), and IVA (ICC value 0.73 ). Two reviewers had moderate agreement on the ECA (ICC value 0.59 ) and IHI (ICC value 0.51). There were excellent intra-observer agreement on the MCs classification (observer 10.98 and observer 2 0.99), grade of DD (observer 10.87 and observer 20.91 ), the LL (observer 10.85 and observer 2 0.83), SS (observer 10.82 and observer 2 0.87 ), IVA (observer 10.88 and observer 20.83 ), IHI (observer 10.85 and observer 2: 0.82), and ECA (observer 10.81 and observer 20.84 ).

\section{Independent risk factors}

Potential variables of interest of the MCs and DD groups are compared in Table 3. In the univariate analysis, significant differences were detected between the MCs and DD groups for the parameters of LL, SS, IHI, ECA, and IVA only at the L5/S1 level. Furthermore, multivariate logistic regression was performed to evaluate the potential factors related to MCs.

To avoid the effect of lumbar levels on the results of the study, we performed a separate logistic regression analysis for each lumbar level. The results of logistic regression analysis showed no significant relationships between age, LL, SS, ECA, IVA, and the development of MCs. A reduction in IHI only at the L3/4 level was associated with the presence of MCs (odds ratio [OR] 7.77; 95\% confidence interval $[\mathrm{CI}] 2.037-29.614 ; p=0.003)$. A 7.77 -fold increased risk was found for the presence of any MCs, with every $1 \%$ reduction in the IHI for the

Table 3 The results of the potential variables of interest

\begin{tabular}{llllll}
\hline Items & & $\begin{array}{l}\text { MCs group } \\
(n=138)\end{array}$ & $\begin{array}{l}\text { DD group } \\
(n=183)\end{array}$ & $Z$ & $p$ \\
\hline $\mathrm{LL}\left(^{\circ}\right)$ & & $33.77 \pm 11.52$ & $39.22 \pm 11.53$ & -4.192 & 0.000 \\
$\mathrm{SS}\left(^{\circ}\right)$ & & $31.55 \pm 8.40$ & $35.20 \pm 7.81$ & -4.007 & 0.000 \\
$\mathrm{IHI}$ & $\mathrm{L} 3 / 4$ & $23.32 \pm 5.05$ & $30.37 \pm 4.17$ & -5.124 & 0.000 \\
& $\mathrm{~L} 4 / 5$ & $27.30 \pm 6.65$ & $32.44 \pm 5.33$ & -5.197 & 0.000 \\
& $\mathrm{~L} 5 / \mathrm{S} 1$ & $30.35 \pm 6.98$ & $34.18 \pm 5.98$ & -4.413 & 0.000 \\
$\mathrm{IVA}\left(^{\circ}\right)$ & $\mathrm{L} 3 / 4$ & $6.14 \pm 2.80$ & $6.10 \pm 2.61$ & -0.258 & 0.796 \\
& $\mathrm{~L} 4 / 5$ & $6.61 \pm 3.58$ & $6.85 \pm 3.80$ & -0.424 & 0.671 \\
& $\mathrm{~L} / \mathrm{S} 1$ & $10.11 \pm 5.43$ & $12.30 \pm 4.87$ & -2.853 & 0.004 \\
$\mathrm{ECA}\left(^{\circ}\right)$ & $\mathrm{L} 3 / 4 \mathrm{U}$ & $159.19 \pm 7.61$ & $164.68 \pm 10.34$ & -3.127 & 0.002 \\
& $\mathrm{~L} 3 / 4 \mathrm{~L}$ & $162.45 \pm 13.78$ & $169.98 \pm 6.67$ & -2.318 & 0.020 \\
& $\mathrm{~L} 4 / 5 \mathrm{U}$ & $160.93 \pm 10.79$ & $165.62 \pm 8.40$ & -2.852 & 0.004 \\
& $\mathrm{~L} 4 / 5 \mathrm{~L}$ & $166.06 \pm 9.39$ & $171.63 \pm 6.45$ & -3.775 & 0.000 \\
& $\mathrm{~L} 5 / \mathrm{S} 1 \mathrm{U}$ & $157.39 \pm 11.29$ & $162.23 \pm 8.02$ & -3.616 & 0.000 \\
& $\mathrm{~L} 5 / \mathrm{S} 1 \mathrm{~L}$ & $167.36 \pm 9.22$ & $171.33 \pm 7.09$ & -3.894 & 0.000 \\
\hline
\end{tabular}


lumbar spine. For a female at the L5/S1 level there was an association with an increased risk of the presence of MCs (OR 2.33; 95\% CI 1.247-4.361; $p=$ 0.008) (Table 4).

\section{Discussion}

\section{Main findings}

The lumbar instability caused by spinal degenerative changes may be an important factor for the development of MCs. However, no previous studies were designed to test the possible relationships. To the best of our knowledge, this is the first study to report on the relationships between multiple sagittal parameters of the lumbar spine and the development of MCs. The results of this study showed negative relationships between the lumbar sagittal parameters and MCs. Furthermore, female sex and a narrow intervertebral space were independent risk factors for the development of MCs at the corresponding lumbar levels. This study also reinforces the strength of the findings from previous studies which have reported that MCs have a high incidence among patients with DD. Interestingly, our study also indicated that BMI might not be associated with MCs in the Chinese population.

\section{Prevalence of MCs}

Previous studies have reported that the incidence of MCs among patients with lumbar DD varies between 19\% and $59 \%$, with type 2 being the most common and L5/S1 being the most common level $[1,9,19-22]$. Our findings were consistent with those of the earlier studies with the conclusions that MCs have a higher incidence among patients with lumbar DD (42.99\%), their prevalence increased with age, and female comprise the majority of MCs cases, with type 2 and L5/S1 being the most common. Some studies $[4,23]$ have reported that the prevalence of MCs among non-clinical populations in Asia was much lower than that in Europe and North America. However, our study indicates that the prevalence rates of MCs were not lower than those in other ethnicities, which may be attributed to the fact that the subjects being recruited in this study were selected DD cases. This study also shows that female sex is a determinant of MCs. Female sex also increased the odds of MCs at the L5/S1 level by 2.3-fold. The high incidence of osteoporosis in females may be one of the

Table 4 The logistic regression analysis of potential factors related to MCs

\begin{tabular}{lllllll}
\hline Risk factors & $\beta$ & SE & Wald & $p$ & OR & $95 \% \mathrm{Cl}$ \\
\hline L3/4 & & & & & & \\
$\| \mathrm{HI}$ & 2.050 & 0.683 & 9.010 & 0.003 & 7.767 & $2.037 \sim 29.614$ \\
L5/S1 & & & & & & \\
Gender & 0.847 & 0.319 & 7.022 & 0.008 & 2.332 & $1.247 \sim 4.361$ \\
\hline
\end{tabular}

reasonable explanations for the high prevalence of MCs in females [24].

In our study, age is associated with an increased risk of MCs among patients with DD, but BMI, CRP, and WBC did not increase the likelihood of MCs. Age and BMI have previously been proven to be related to the occurrence of MCs [5, 19]. Interestingly, our study showed no significant differences in BMI between the two groups. A recent population-based study [4] conducted with a Chinese population reported that no significant differences were found in BMI. A plausible explanation may be due to the BMI not increasing the likelihood of MCs in the Chinese population. MCs have been proven to be strongly associated with CLBP [20]. Park et al. [25] reported that CRP is not a predictor in patients with CLBP, and our findings are consistent with those of the earlier studies.

\section{Lumbar sagittal parameters}

LL is unique to the human spine and develops an upright posture as facilitation progresses, and loss of LL causes irregular stress distribution on the spine [26]. SS is used to evaluate the normal variation in the sagittal plane of the adult human lumbar spine and pelvis in the standing position [27]. A recent study reported by Xia et al. [28] supports that the amount of MCs was significantly correlated with LL and SS. This is coincident with our study. The associations of LL and SS with risk of MCs may be due to decreased axial decompression ability of the spine and an increased shear force on the vertebral endplate [28]. This would increase the risk of endplate and cancellous bone damage when the spine is subjected to external forces in the perpendicular direction [29].

The IHI, as a quantitative and continuous measure, and the relationships between IHI and DD, were explored in a study by Teichtahl [30] that supported the idea that a negative dose-response relationship exists between the increasing severity of DD and a reduction of the IHI. For every $1 \mathrm{~mm}$ reduction in the total intervertebral disc height for the lumbar spine, there was a 1.1-fold increased risk for the presence of MCs, which was described by Teichtahl [31]. In the present study, we observed that the IHI is significantly associated with an increased risk of MCs, which may be due to a decreased IHI attenuation of the cushioning effect and load redistribution to adjacent vertebrae, resulting in MCs [31]. In the multivariate logistic regression, after adjusting for age, WBC, BMI, and CRP, a reduction in the IHI at the L3/L4 level was associated with the presence of MCs. There was a 7.77-fold increased risk for the presence of any MCs with every $1 \%$ reduction in the IHI for the lumbar spine. 
Endplate concavity is conducive to humans for longterm adaptation to pressure stress and dispersion of axial stress [32]. The present study supports a negative correlation between MCs and the vertebral ECA. A previous study [32] reporting on the associations of the ECA with severity of DD indicated that as the ECA increased, with the endplate becoming flat, closely correlated with the severity of the DD. However, this study did not report that the ECA is associated with MCs. Li et al. [33] demonstrated that the incidence of MCs increased with the change in sagittal endplates from concave to flat to irregular and indicated that an irregular shape of the endplate is significantly associated with MCs. It is important to note that the ECA will be deceased with the change in sagittal endplates from flat to irregular. Our finding is consistent with the findings of $\mathrm{Li}$ et al., which may be due to the endplate remodeling involved in the pathogenesis of MCs and can be considered a response to abnormal segmental mobility [33]. However, compared with the shape of the endplate that was used to designate the level as concave, flat, and irregular, the ECA is a more precise measure of the shape of the endplate.

In addition, our study indicates that significant differences were detected between the MCs and DD groups for IVA, but only at the L5/S1 level. Hayashi et al. [34] reported that a significant decrease of angular motion was found in segments with MCs in the severe DD stage. Their study was consistent with our finding because decreased or collapsed disc height due to DD would result in decreased IVA and angular motion.

\section{Limitations}

The present study has several limitations. One major drawback of this study is the retrospective nature of this study which makes it difficult to control some variables inherent for patients with MCs. Importantly, a lack of whole spine radiographs forced us to abandon the measurement and analysis of pelvic parameters due to the cost to the patient and local medical insurance policies. In addition, the development of MCs has been well known to be a dynamic process, and lumbar sagittal parameters may be affected by different types of MCs. Thus, another problem of this study is that it did not consider all types of MCs because of a limitation of the sample size. Although complete elimination of the measurement error is impossible, we attempted to keep the measurement error within acceptable tolerance. Finally, the possibility of selection bias exists in this study.

\section{Conclusions}

In conclusion, DD and lumbar level should be considered in evaluating the relationships between lumbar sagittal parameters and the development of MCs. This study reinforces the strength of the findings from previous studies, which reported that MCs have a high incidence among patients with DD. Interestingly, it also indicated that BMI might be not associated with MCs for the Chinese population. The results of lumbar sagittal parameters for patients in the MCs group were worse than those in the DD group, indicating that lumbar sagittal parameters were negatively associated with the development of MCs. Furthermore, the results of logistic regression analysis suggested that the narrow intervertebral space was the independent risk factor for the development of MCs at the L3/L4 level. However, the positive role of sex was only found for MCs at the L5/S1 level.

\section{Abbreviations \\ MCs: Modic changes; MRI: Magnetic resonance imaging; CLBP: Chronic low back pain; DD: Disc degeneration; LL: Lumbar lordosis;; SS: Sacral slope; IHI: Intervertebral height index; ECA: Endplate concave angle; IVA: Intervertebral angle}

\section{Acknowledgements}

Not applicable.

\section{Authors' contributions}

X.P.M. and Y.F.O. conceived and designed the study. X.P.M., W.P., C.L.W., and M.D.L. collected the data. X.P.M. W.P., and J.X. analyzed and interpreted the patient data. X.P.M. W.P., and C.L.W. wrote the paper. All authors read and approved the final manuscript. All authors have read the journal policies and have no issues relating to journal policies. All authors have seen the manuscript and approved to submit to your journal. The work described has not been submitted elsewhere for publication, in whole or in part.

\section{Funding}

This work was supported by the Key Scientific Research Projects for Medicine and Health of Guangxi Zhuang Autonomous Region (grant no. Emphasis

2010029 and no. S2018026) and China Scholarship Council (no. 2018018180151).

Availability of data and materials

The datasets generated and analyzed during the current study are available from the corresponding author on reasonable request.

Ethics approval and consent to participate

This study has obtained ethics approval and consent of the ethics committee in our hospital (no. 2016-12).

Consent for publication

Not applicable.

\section{Competing interests}

All authors have no conflicts of interest to report.

\section{Author details}

${ }^{1}$ Department of Orthopedics, People's Hospital of Guangxi Zhuang Autonomous Region, Nanning 530021, China. ${ }^{2}$ Institute of Anatomy and Cell Biology, Justus-Liebig-University, 35392 Giessen, Germany. ${ }^{3}$ Faculty of Acupuncture, Guangxi University of Chinese Medicine, Nanning 530001, China.

Received: 4 February 2020 Accepted: 5 June 2020 Published online: 15 June 2020

\section{References}

1. De Roos A, Kressel H, Spritzer C, Dalinka M. MR imaging of marrow changes adjacent to end plates in degenerative lumbar disk disease. Am J Roentgenol. 1987;149(3):531-4

2. Modic MT, Steinberg PM, Ross JS, Masaryk TJ, Carter JR. Degenerative disk disease: assessment of changes in vertebral body marrow with MR imaging. Radiology. 1988;166(1 Pt 1):193-9. 
3. Modic MT, Masaryk TJ, Ross JS, Carter JR. Imaging of degenerative disk disease. Radiology. 1988;168(1):177-86.

4. Mok FP, Samartzis D, Karppinen J, Fong DY, Luk KD, Cheung KM. Modic changes of the lumbar spine: prevalence, risk factors, and association with disc degeneration and low back pain in a large-scale population-based cohort. Spine J. 2016;16(1):32-41.

5. Määttä JH, Wadge S, MacGregor A, Karppinen J, Williams FM. ISSLS prize winner: vertebral endplate (Modic) change is an independent risk factor for episodes of severe and disabling low back pain. Spine (Phila Pa 1976). 2015; 40(15):1187-93.

6. Dudli S, Liebenberg E, Magnitsky S, Lu B, Lauricella M, Lotz JC. Modic type 1 change is an autoimmune response that requires a proinflammatory milieu provided by the 'Modic disc'. Spine J. 2018;18(5):831-44.

7. Albert HB, Kjaer $P$, Jensen TS. Modic changes, possible causes and relation to low back pain. Med Hypotheses. 2008;70(2):361-8.

8. Georgy MM, Vaida F, Stern M, Murphy K. Association between type 1 Modic changes and propionibacterium acnes infection in the cervical spine: an observational study. AJNR Am J Neuroradiol. 2018;39(9):1764-7.

9. Zhang F, Wang H, Xu H, Shao M, Lu F, Jiang J, et al. Radiologic analysis of kinematic characteristics of modic changes based on lumbar disc degeneration grade. World Neurosurg. 2018:114:e851-6.

10. Buttermann GR, Heithoff KB, Ogilvie JW, Transfeldt EE, Cohen M. Vertebral body MRI related to lumbar fusion results. Eur Spine J. 1997;6(2):115-20.

11. Lamartina C, Berjano P, Petruzzi M, Sinigaglia A, Casero G, Cecchinato R, et al. Criteria to restore the sagittal balance in deformity and degenerative spondylolisthesis. Eur Spine J. 2012;21(Suppl.1):S27-31.

12. Videbaek TS, Bünger CE, Henriksen M, Neils E, Christensen FB. Sagittal spinal balance after lumbar spinal fusion: The impact of anterior column support results from a randomized clinical trial with an eight- to thirteen-year radiographic follow-up. Spine (Phila Pa 1976). 2011;36(3):183-91.

13. Glassman SD, Berven S, Bridwell K, Horton W, Dimar JR. Correlation of radiographic parameters and clinical symptoms in adult scoliosis. Spine (Phila Pa 1976). 2005;30(6):682-8.

14. Li J, Qin S, Li Y, Shen Y. Modic changes of the cervical spine: T1 slope and its impact on axial neck pain. J Pain Res. 2017;10:2041-5.

15. Wu JP, Wang QB, Feng XJ, Wang Q, Cheng MH. Relationship between Modic changes and sagittal balance parameters in the cervical spine. Med Sci Monit. 2018;24:6102-6.

16. Schroeder K, Richards S. Non-specific low back pain. Lancet. 2012;37(9814): 482-91

17. Van Tulder M, Becker A, Bekkering T, Breen A, del Real MT, Hutchinson A, et al. Chapter 3 European quidelines for the management of acutenonspecific low back pain in primary care. European spine journal. 2006:15:169-91.

18. Pfirrmann CW, Metzdorf A, Zanetti M, Hodler J, Boos N. Magnetic resonance classification of lumbar intervertebral disc degeneration. Spine (Phila Pa 1976). 2001;26:1873-8.

19. Kuisma M, Karppinen J, Niinimäki J, Kurunlahti M, Haapea M, Vanharanta $H$, et al. A three-year follow-up of lumbar spine endplate (Modic) changes. Spine (Phila Pa 1976). 2006;31(15):1714-8.

20. Kuisma M, Karppinen J, Niinimäki J, Ojala R, Haapea M, Heliövaara M, et al. Modic changes in endplates of lumbar vertebral bodies: prevalence and association with low back and sciatic pain among middle-aged male workers. Spine (Phila Pa 1976). 2007;32(10):1116-22.

21. Rahme R, Moussa R. The modic vertebral endplate and marrow changes: pathologic significance and relation to low back pain and segmental instability of the lumbar spine. AJNR Am J Neuroradiol. 2008:29:838-42.

22. Braithwaite I, White J, Saifuddin A, Renton P, Taylor BA. Vertebral end-plate (Modic) changes on lumbar spine MRI: correlation with pain reproduction at lumbar discography. Eur Spine J. 1998;7(5):363-8.

23. Jensen TS, Karppinen J, Sorensen JS, Niinimäki J, Leboeuf-Yde C. Vertebral endplate signal changes (Modic change): a systematic literature review of prevalence and association with non-specific low back pain. Eur Spine J. 2008;17(11):1407-22

24. Han C, Kuang MJ, Ma JX, Ma XL. Prevalence of Modic changes in the lumbar vertebrae and their associations with workload, smoking and weight in northern China. Sci Rep. 2017;7:46341.

25. Park $\mathrm{CH}$, Lee $\mathrm{SH}$. Prognostic usefulness of high sensitivity C-reactive protein for transforaminal epidural steroid injection in patients with radicular pain. Pain Medicine. 2011;12:219-23.
26. Lee CH, Chung CK, Jang JS, Kim SM, Chin DK, Lee JK. 'Lumbar degenerative kyphosis'is not byword for degenerative sagittal imbalance: time to replace a misconception. J Korean Neurosurg Soc. 2017;60(2):125-9.

27. Roussouly P, Gollogly S, Berthonnaud E, Dimnet J. Classification of the normal variation in the sagittal alignment of the human lumbar spine and pelvis in the standing position. Spine (Phila Pa 1976). 2005;30(3):346-53.

28. Xia W, Liu C, Duan S, Xu S, Wang K, Zhu Z, et al. The influence of spinalpelvic parameters on the prevalence of endplate Modic changes in degenerative thoracolumbar/lumbar kyphosis patients. PLoS One. 2018; 13(5):e0197470.

29. Sheng-yun L, Letu S, Jian C, Mamuti M, Jun-hui L, Zhi S, et al. Comparison of modic changes in the lumbar and cervical spine, in 3167 patients with and without spinal pain. PLoS One. 2014;9(12):e114993.

30. Teichtahl AJ, Urquhart DM, Wang Y, Wluka AE, Heritier S, Cicuttini FM. A Dose-response relationship between severity of disc degeneration and intervertebral disc height in the lumbosacral spine. Arthritis Res Ther. 2015; 17:297.

31. Teichtahl AJ, Urquhart DM, Wang Y, Wluka AE, O'Sullivan R, Jones G, et al. Modic changes in the lumbar spine and their association with body composition, fat distribution and intervertebral disc height - a 3.0 T-MRI study. BMC Musculoskelet Disord. 2016;17:92.

32. Xiao L, Ni C, Shi J, Wang Z, Wang S, Zhang J, et al. Analysis of correlation between vertebral endplate change and lumbar disc degeneration. Med Sci Monit. 2017;23:4932-8.

33. Li Y, Lord E, Cohen Y, Ruangchainikom M, Wang B, Lv G, et al. Effects of sagittal endplate shape on lumbar segmental mobility as evaluated by kinetic magnetic resonance imaging. Spine (Phila Pa 1976). 2014;39(17): E1035-41.

34. Hayashi T, Daubs MD, Suzuki A, Scott TP, Phan KH, Ruangchainikom M, et al. Motion characteristics and related factors of Modic changes in the lumbar spine. J Neurosurg Spine. 2015;22(5):511-7.

\section{Publisher's Note}

Springer Nature remains neutral with regard to jurisdictional claims in published maps and institutional affiliations.

Ready to submit your research? Choose BMC and benefit from:

- fast, convenient online submission

- thorough peer review by experienced researchers in your field

- rapid publication on acceptance

- support for research data, including large and complex data types

- gold Open Access which fosters wider collaboration and increased citations

- maximum visibility for your research: over $100 \mathrm{M}$ website views per year

At $\mathrm{BMC}$, research is always in progress.

Learn more biomedcentral.com/submission 